\title{
DNA-Mediated Charge Transport Requires Conformational Motion of the DNA Bases: Elimination of Charge Transport in Rigid Glasses at $77 \mathrm{~K}$
}

Melanie A. O'Neill, and Jacqueline K. Barton

Division of Chemistry and Chemical Engineering, California Institute of Technology, Pasadena, California 91125

\section{Supporting Information}
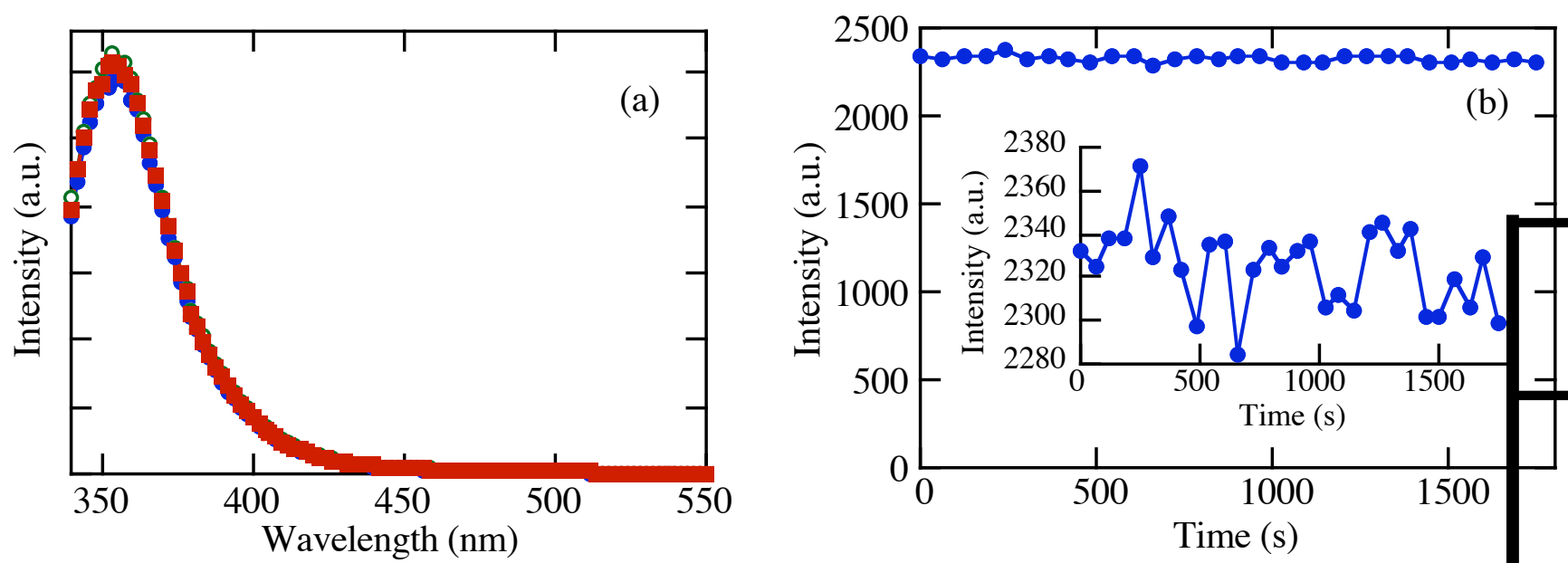

Figure S-1. Reproducibility (a) and stability (b) of $10 \mathrm{M}$ aqueous LiCl glasses, as monitored by the fluorescence emission of photoexcited 2-aminopurine ( $\mathrm{Ap}^{*}, 25 \mu \mathrm{M}, \lambda \mathrm{ex}=325 \mathrm{~nm}$ ). Shown in (a) are the emission spectra of obtained in three independently prepared glassy matrices at 77 $\mathrm{K}$. These emission spectra are very stable over periods of at least several hours. Shown in (b) is the variation in emission intensity $\mathrm{Ap}^{*}$ (monitored at $\lambda \max =360 \mathrm{~nm}$ ) in a $\mathrm{LiCl}$ glass at $77 \mathrm{~K}$ as a function of time (total time of 30 minutes). The expanded plot (inset) reveals intensity fluctuation of $<5 \%$. Similar results were observed for Ap-DNA samples. 


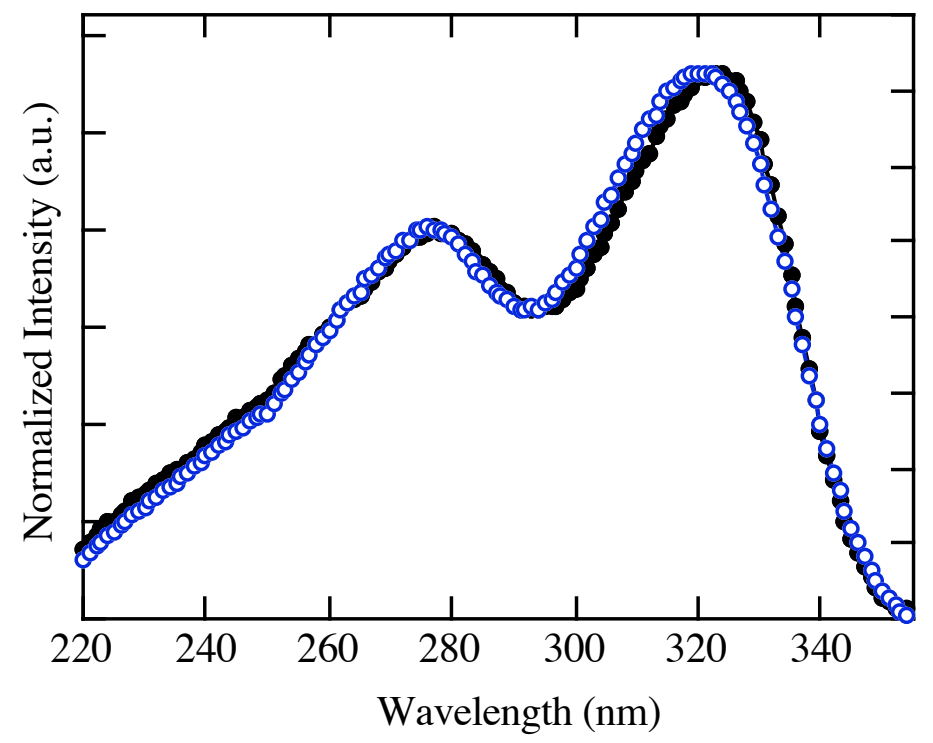

Figure S-2. Fluorescence excitation spectra $(\lambda \mathrm{em}=370 \mathrm{~nm})$ of $2.5 \mu \mathrm{M}$ ApA4I in $100 \mathrm{mM}$ sodium phosphate $\mathrm{pH} 7$ (closed circles) and $10 \mathrm{M} \mathrm{LiCl} \mathrm{pH} 7$ (open circles) at ambient temperature $(\sim 298 \mathrm{~K})$ The lower duplex concentration is necessary due to the strong absorption of the natural DNA bases at $\lambda<300 \mathrm{~nm}$. 
Table S-1. A comparison of the photophysical properties of Ap-DNA assemblies, and yield of charge transport between $\mathrm{Ap}^{*}$ and $\mathrm{G}$ in $10 \mathrm{M} \mathrm{LiCl} \mathrm{pH} 7$ versus $100 \mathrm{mM}$ sodium phosphate $\mathrm{pH} 7$ (NaP) at ambient temperature $(\sim 298 \mathrm{~K})$.

\begin{tabular}{ccccccc}
\hline Sample $^{\mathrm{a}}$ & \multicolumn{2}{c}{$\boldsymbol{\Phi}_{\text {rel }} \mathbf{Y}=\mathbf{I}^{\mathrm{b}}$} & \multicolumn{2}{c}{ Anisotropy $\mathbf{Y = \mathbf { I } ^ { \mathrm { c } }}$} & \multicolumn{2}{c}{$\mathbf{F q}(\mathbf{2 9 8} \mathbf{~ K})^{\mathrm{d}}$} \\
\hline & $\mathrm{NaP}$ & $\mathrm{LiCl}$ & $\mathrm{NaP}$ & $\mathrm{LiCl}$ & $\mathrm{NaP}$ & $\mathrm{LiCl}$ \\
\cline { 2 - 7 } & & & & & & \\
ApY & 0.1 & 0.1 & 0.25 & 0.26 & 0.87 & $0 ., 68$ \\
ApAY & 0.06 & 0.1 & 0.23 & 0.25 & 0.47 & 0.47 \\
ApA2Y & 0.04 & 0.06 & 0.25 & 0.24 & 0.20 & 0.23 \\
ApA3Y & 0.03 & 0.05 & 0.26 & 0.23 & 0.24 & 0.18 \\
ApA4Y & 0.04 & 0.07 & 0.23 & 0.23 & 0.14 & 0.14 \\
\hline
\end{tabular}

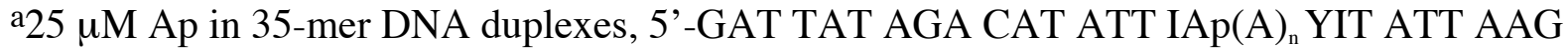
TAC ATT AC-3', Y=I,G, in $10 \mathrm{M} \mathrm{LiCl,} \mathrm{pH} 7$ or $100 \mathrm{mM}$ sodium phosphate $\mathrm{pH} 7$ at $298 \mathrm{~K}$.

${ }^{b}$ Fluorescence yields relative to Ap in respective solution $\left(\lambda_{\mathrm{ex}}=325 \mathrm{~nm}\right)$.

${ }^{\mathrm{c}}$ Monitored at $370 \mathrm{~nm}$.

${ }^{\mathrm{d}}$ Evaluated as $\mathrm{Fq}=1-\Phi_{\mathrm{G}} / \Phi_{\mathrm{I}}$, relative uncertainties $\pm 10 \%$. 